(c) American Dairy Science Association, 2004.

\title{
Hyperketonemia Impairs Glucose Metabolism in Pregnant and Nonpregnant Ewes
}

\author{
C. Schlumbohm and J. Harmeyer \\ Department of Physiology \\ School of Veterinary Medicine \\ Bischofsholer Damm 15/102 \\ 30173 Hannover, Germany
}

\begin{abstract}
The present study was undertaken to test the hypothesis that high ketone body concentrations suppress endogenous production of glucose and in pregnant sheep facilitate development of pregnancy toxemia. Rates of endogenous glucose production $\left[\mathrm{mmol} \cdot \mathrm{min}^{-1}\right]$, and rate constants of glucose turnover $\left[\mathrm{min}^{-1}\right]$ were measured in seven 12-h fasted sheep in the presence of normoand hyperketonemia by use of $\mathrm{D}-2-\left[{ }^{3} \mathrm{H}\right]$-glucose. The measurements were carried out in the same sheep during the nonpregnant nonlactating state, during late pregnancy (10 $\pm 7 \mathrm{~d}$ antepartum) and during lactation (19 $\pm 6 \mathrm{~d}$ postpartum). Hyperketonemia ( 5 to $7 \mathrm{mmol}$. $\mathrm{L}^{-1}$ ), similar to that present in spontaneous ovine pregnancy toxemia, was induced by continuous intravenous 4 -h infusions of DL- $\beta$-hydroxybutyrate (DL-BHB). Glucose turnover $\left[\mathrm{mmol} \cdot \mathrm{min}^{-1}\right]$ in the same 7 nonpregnant nonlactating, late pregnant, and lactating sheep was significantly greater during normoketonemia $(0.80$, $1.16,1.76)$ than during hyperketonemia $(0.66,0.92$, 1.16 , respectively). The rate constants of glucose turnover were not altered by elevation of the BHB concentration. The results demonstrated that high BHB concentrations significantly suppressed endogenous glucose production but showed no effect on glucose utilization. The suppressive effect of hyperketonemia on hepatic glucose production resulted in a significant reduction of plasma glucose concentration and was qualitatively the same in all three reproductive states. The results indicate that hyperketonemia, which is regularly present in late twin pregnant hypoglycemic sheep contributes significantly to the reduction of available glucose. This effect of hyperketonemia may invoke sustained hypoglycemia and may render the ewe into a vicious cycle that probably makes the animal refractory to treatment in most cases.
\end{abstract}

Received September 2, 2003.

Accepted May 13, 2003.

Corresponding author: C. Schlumbohm; e-mail: Christina. Schlumohm@tiho-hannover.de.
(Key words: glucose kinetics, sheep, ketosis)

Abbreviation key: D-BHB = D- $\beta$-hydroxybutyrate, DL-BHB $=$ DL- $\beta$-hydroxybutyrate, AcAc $=$ acetoacetate, $\mathbf{N A D}=\beta$-nicotinamide adenine dinucleotide, $\mathbf{M E}=$ metabolizable energy, $\mathbf{N A D H}=\beta$-nicotinamide adenine dinucleotide, reduced form, $\mathbf{N}=$ number of experiments, $\mathbf{n}=$ number of measurements, $\mathbf{R M}=$ repeated measures.

\section{INTRODUCTION}

Ruminants usually show higher ketone body concentrations in blood plasma than monogastric animals due to postprandial production of D- $\beta$-hydroxybutyrate (DBHB) in the ruminal epithelium (Heitmann and Fernandez, 1986). Still higher concentrations of ketone bodies are present in ruminants suffering from clinical or subclinical ketosis (Herdt et al., 1981). A negative energy balance during the transition period around birth is regarded as the primary cause for the development of the disease and the development of hyperketonemia in ewes (Van Saun, 2000; Lacetera et al., 2001) and dairy cows (Gerloff, 2000; Herdt, 2000). Sustained hyperketonemia is probably the most characteristic biochemical sign of spontaneous clinical and subclinical ketosis of sheep and cattle (Geishauser et al., 1998; Enjalbert et al., 2001). In ketotic animals, when feed intake has ceased ketone bodies are almost exclusively produced by the liver from $\beta$-oxidation products of fatty acids (Heitmann et al., 1987; Lean et al., 1992).

Ketone bodies serve as an alternative fuel for many tissues (Robinson and Williamson, 1980), but they probably do not or only to a minor extent contribute to the energy supply of the fetus (Morriss et al., 1974; Battaglia and Meschia, 1988). Glucose remains the most important metabolite for fetal and placental growth. The ability of the ewe to provide a sufficient amount of glucose to the fetus from dietary sources is limited because about 70 to $75 \%$ of the dietary carbohydrate is converted in the rumen into nonglucogenic products. The remaining fraction of digestible carbohydrate provides 40 to $60 \%$ of the circulating glucose 
through propionate (Bergman, 1973; Weekes, 1979). During periods of a negative energy balance and increased demand for glucose, up to $23 \%$ of the glucose may be synthesized from liberated glycerol from the adipose tissue (Bergman et al., 1968; Weekes, 1979). Along with this glucogenic precursor, a larger amount of fatty acids is released into the circulation that may give rise to an increased rate of ketone body formation. Although the overall metabolic situation of the ketotic animal has long been recognized, there is still much uncertainty about the nature of the first metabolic changes that are associated with the onset of the disease (Kronfeld, 1971; Bergman, 1973). In this context, hyperketonemia has usually been regarded a symptom rather than a causative factor in the development of the disease (Baird et al., 1974; Marteniuk and Herdt, 1988; Lean et al., 1992).

Based on studies carried out with humans (Beylot et al., 1986; Baron et al., 1989), dogs (Mebane and Madison, 1964; Shaw and Wolfe, 1984), and pigs (Müller et al., 1984), there is reason to believe that elevated concentrations of ketone bodies in blood are not just a symptom of the ketotic derangement but may play an active causative role during the onset of the disease. However, glucose metabolism of monogastric mammals including its hormonal control differs in many respects from that of ruminants. Therefore, it appeared of interest to examine the question whether elevated concentrations of ketone bodies in blood plasma of sheep exert a specific adverse effect on the animal that might influence the development and the outcome of clinical ketosis. For the study of this problem, kinetic parameters of glucose metabolism were measured in ewes during normo- and hyperketonemia. Measurements were carried out in the same sheep during three reproductive states, in the dry nonpregnant state, during late pregnancy and during lactation after an overnight fast. The study revealed that hyperketonemia significantly depressed hepatic glucose production.

\section{MATERIALS AND METHODS}

\section{Chemicals}

D-2- $\left[{ }^{3} \mathrm{H}\right]$-Glucose with specific activities from 0.74 to 1.11 TBq. $\mathrm{mmol}^{-1}$ was purchased from DuPont de Nemours (NEN, Zaventem, Belgium). Na-DL- $\beta$-Hydroxybutyrate was synthesized as described previously (Schlumbohm and Harmeyer, 1999). The proportion of the D-BHB in the racemate, the infusate, in plasma, and urine was quantified by an enzymatic assay with $\beta$-nicotinamide adenine dinucleotide (NAD), D-BHB dehydrogenase, and DL- $\beta$-hydroxybutyric acid as standard. These ingredients were obtained from Roche Diagnostics (Mannheim, Germany). All other chemicals were from Merck (Darmstadt, Germany) and were of analytical grade.

\section{Ethical Standards}

The animal experiments were approved by the ethical committee on animal rights protection of the Hannover District Government in accordance with German legislation on animal rights and welfare. Germany has signed and ratified the European convention for the protection of vertebrate animals used for experimental and other scientific purposes of March 18, 1986. The German legislation conforms to the requirements of this convention and guidelines prepared for compliance. The study has also been carried out in accordance with the Principles of Laboratory Animal Care (NIH Publication no. 85-23, revised 1985).

\section{Experimental Animals}

Seven healthy nonketotic ewes were used for the study. They were purchased from a local breeder as pregnant ewes, which were in their third or later pregnancy. Three of the animals were Texel and 4 were German Blackface. These 7 animals were used for all experiments, which were carried out in 3 reproductive states; during late pregnancy (10 $\pm 7 \mathrm{~d}$ antepartum, $\bar{x}$ $\pm \mathrm{SD})$, during lactation ( $19 \pm 6 \mathrm{~d}$ postpartum) and in the nonpregnant nonlactating state ( $>6 \mathrm{wk}$ after weaning of the lambs). The weight of the sheep ranged from 64 to $92 \mathrm{~kg}$ (Table 1). The animals were maintained indoors in pens with beddings in groups and fed hay with $10.9 \%$ $\mathrm{CP}(\mathrm{N} \cdot 6.25), 8.2 \%$ ash, $8.7 \mathrm{MJ}$ of $\mathrm{ME} / \mathrm{kg} \mathrm{DM}$ ad libitum. Water was accessible at all times. Gestational age and the number of fetuses were examined by ultrasonography. Three of the ewes had single lambs and 4 carried twins. During the last 6 wk of pregnancy and during the first 6 wk of lactation the hay ration was supplemented twice daily with concentrate feed (Club-Schafkraft, Club-Kraftfutterwerke Nord, Hamburg, Germany) containing $17 \% \mathrm{CP}(\mathrm{N} \cdot 6.25), 1.5 \% \mathrm{Ca}, 0.5 \% \mathrm{P}$, and 10.2 $\mathrm{MJ}$ of $\mathrm{ME} \cdot \mathrm{kg}^{-1}$. Sheep carrying or suckling twins received $1000 \mathrm{~g}$ of concentrate per day, and those with one offspring were given $500 \mathrm{~g}$ per day. The experiments were carried out after hay and concentrate had been withheld over night (for $12 \mathrm{~h}$ ). During the experiments, the experimental animal and one companion animal were separated from their group and moved into the laboratory. The experimental animal was placed into a metabolic crate. Twenty experiments were performed. One to two days before an experiment started, both external jugular veins were catheterized (polyethylene tubing, i.d. $0.86 \mathrm{~mm}$ ). The catheters were filled with saline $(0.9 \%$ weight per volume) that contained 750 
Table 1. Parameters of glucose metabolism from 7 normo- and hyperketonemic sheep during 3 different reproductive states $(\overline{\mathrm{x}} \pm$ SD).

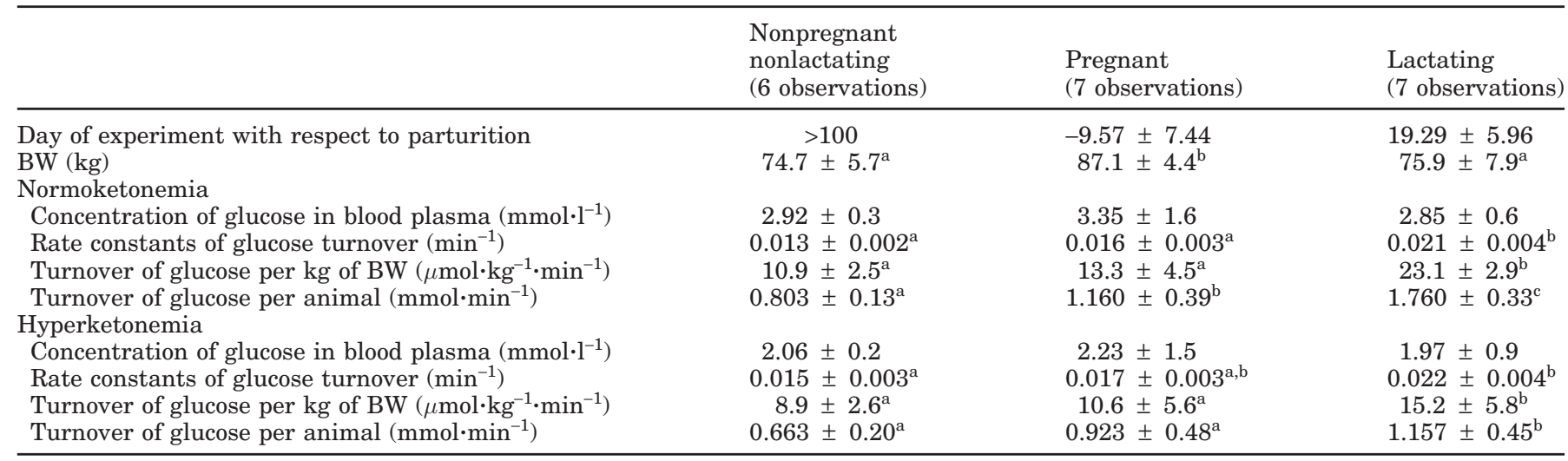

${ }^{\mathrm{a}, \mathrm{b}, \mathrm{c}}$ Different superscripts denote significant differences $(P<0.05)$.

units $\cdot \mathrm{mL}^{-1}$ of heparin (Na-heparin, U.S.P. XXI, Roth, Karlsruhe, Germany) and covered by a bandage around the neck.

\section{Experimental Setup}

The experimental setup is illustrated in Figure 1. At least $1 \mathrm{~h}$ before the start of measurements, the experimental sheep and its companion animal were moved into the laboratory. One catheter was used for infusions and the other for blood collection. Sixteen venous blood samples were drawn in heparinized tubes, $10 \mathrm{~mL}$ each (Na-Heparin Monovetten, Sarstedt, Nürmbrecht, Germany). The samples were immediately placed on ice and stored until the end of the experiment. A bolus of 1.85 MBq D-2- $\left[{ }^{3} \mathrm{H}\right]$-glucose, diluted in $5 \mathrm{~mL}$ of a sterile solution with $10 \%$ glucose was administered by single intravenous injection for measurement of basal glucose

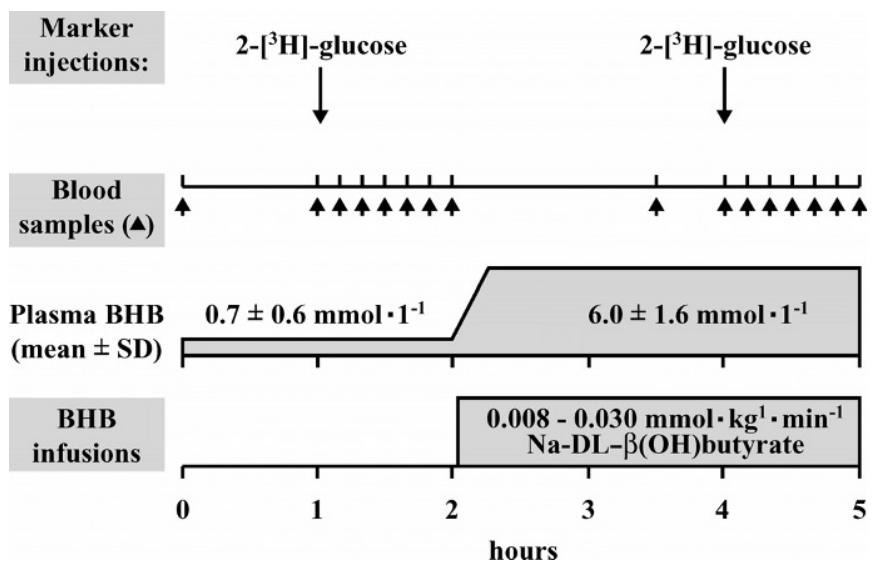

Figure 1. Experimental setup for measurement of glucose metabolism in blood plasma during normo- and hyperketonemia. The same setup was used during late pregnancy, during peak lactation, and after weaning of the lambs. turnover. Serial blood samples were taken immediately before bolus injection and for 60 min thereafter, in 10min intervals. Sixty minutes after application of the first glucose marker, a continuous infusion of DL-BHB was started to elevate the plasma BHB concentration up to 4 to $7 \mathrm{mmol} \cdot \mathrm{L}^{-1}$. The elevated $\mathrm{BHB}$ concentrations were similar to those present in sheep during pregnancy toxemia (Henze et al., 1998). Infusion rates of DL-BHB were adjusted to the tolerance range of the individual sheep. The tolerance rate was determined in a pilot DLBHB load experiment $1 \mathrm{~d}$ before (see below). The DLBHB infusate solution was adjusted to $\mathrm{pH} 7.4$ before use, filtered, and autoclaved. The infusion rate was monitored by continuous weighing of the reservoir bottle. After $2 \mathrm{~h}$ of DL-BHB infusion, the D-BHB level in plasma had reached a steady state. At this time a second dose of $1.85 \mathrm{MBq}$ of $2-\left[{ }^{3} \mathrm{H}\right]$-glucose was intravenously applied to the animal to measure glucose turnover during the DL-BHB load (Figure 1). Serial blood samples were again collected, 2 before and 6 after the second marker injection in 10-min intervals. The assignment of the plasma samples to the various analyses is listed in Table 2.

\section{Preceding BHB Tolerance Tests}

To estimate the DL-BHB dose that elevated blood DBHB concentration up to the desired level of 5 to 7 $\mathrm{mmol} \cdot \mathrm{L}^{-1}$, a pilot experiment was carried out with each sheep $1 \mathrm{~d}$ before the main experiment started. In this experiment the i.v. infusion rate of DL-BHB was stepwise increased over $3 \mathrm{~h} \mathrm{by} 0.003 \mathrm{mmol} \cdot \mathrm{kg}^{-1} \cdot \mathrm{min}^{-1}$ (from 0.009 to $0.036 \mathrm{mmol} \cdot \mathrm{kg}^{-1} \cdot \mathrm{min}^{-1}$ ) in 20 -min intervals. Blood samples were collected before the DL-BHB infusion started and during the infusion in 20-min intervals. The D-BHB concentrations in plasma samples were immediately analyzed for BHB content. The BHB infusion rate that gave the desired $\mathrm{BHB}$ concentration 
Table 2. Sampling scheme and analyses of plasma samples.

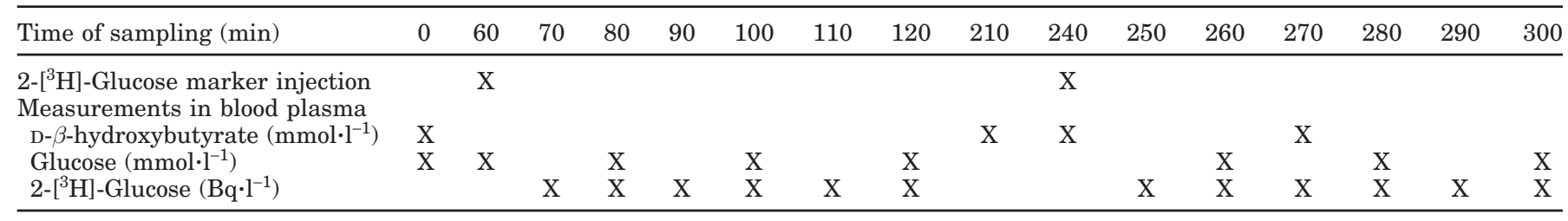

was used during the main experiment on the following day.

\section{Laboratory Methods}

Heparinized blood samples were centrifuged at 3000 $\times g$ for $10 \mathrm{~min}$. Each plasma sample was divided into 3 subsamples and stored at $-20^{\circ} \mathrm{C}$ until analysis. For determination of D-BHB in plasma, aliquots were deproteinized by mixing 1 volume of plasma with 1 volume of $1 \mathrm{M} \mathrm{HClO}_{4}$ and centrifuged ( $10 \mathrm{~min}, 3000 \times g, 4^{\circ} \mathrm{C}$ ). One volume of supernatant was neutralized with 0.1 volume of $1 \mathrm{M} \mathrm{K}_{3} \mathrm{PO}_{4}$ and recentrifuged. The D-BHB was measured in the supernatant by the method of Williamson et al. (1962). For calculation of the D-BHB content, the molar coefficient of extinction of $\mathrm{NADH}$ was used. This is linearly related to the molar concentration of D-BHB in the sample. A standard solution is not required for this assay but was always included as a control. For duplicate measurements, the coefficient of variation was $4.6 \pm 3.9 \%(\bar{x} \pm \mathrm{SD}, \mathrm{n}=160)$. For the standard solution the coefficient of variation between assays was $5.5 \pm 4.6 \%(\bar{x} \pm \mathrm{SD} ; \mathrm{n}=53)$. Glucose was determined in heparinized blood plasma with a reflection photometer (Reflolux, Roche Diagnostics, Mannheim, Germany). The glucose concentration measured with this method differed less than 5\% $(\mathrm{n}=40)$ from the photometrically determined concentration using the Glucose-Perid method (Roche Diagnostics, Mannheim, Germany). For measurement of D-2- $\left[{ }^{3} \mathrm{H}\right]$-glucose radioactivity, 1-mL plasma samples were deproteinized by the method of Somogyi (1952), with $0.25 \mathrm{M} \mathrm{Ba(OH})_{2}$ and $5.65 \% \mathrm{ZnSO}_{4}$ and were centrifuged at $4^{\circ} \mathrm{C}$ for 20 $\mathrm{min}$ at $3000 \times \mathrm{g}$. Supernatants were decanted into scintillation vials, lyophilized to remove $\left[{ }^{3} \mathrm{H}\right]$-water, resolved in $2.0 \mathrm{~mL}$ of deionized water, and mixed with 14 $\mathrm{mL}$ of scintillation cocktail (Hydroluma, Baker, GroßGerau, Germany). The D-2- $\left[{ }^{3} \mathrm{H}\right]$-glucose radioactivity was measured in a liquid scintillation counter (Tri-Carb 2500 TR, Canberra-Packard, Frankfurt, Germany) for $10 \mathrm{~min}$.

\section{Calculation of Glucose Turnover}

The turnover of glucose was calculated by using a noncompartmental approach as described by Shipley and Clark (1972) and modified by Schlumbohm and Harmeyer (1999). Turnover of glucose was calculated in $1 \mathrm{~L}$ of distribution volume. The values were related to unit BW by multiplication with the distribution volume.

Abbreviations used for calculation of glucose kinetics. The following abbreviations were used in this study for calculation of glucose kinetics:

$$
\begin{aligned}
\mathrm{A}= & {\left[{ }^{3} \mathrm{H}\right] \text {-glucose radioactivity per liter of } } \\
& \text { blood plasma }\left[\mathrm{Bq} \cdot \mathrm{L}^{-1}\right] ; \\
(\mathrm{A})_{\mathrm{t}}= & {\left[{ }^{3} \mathrm{H}\right] \text {-glucose radioactivity per liter of } } \\
& \text { blood plasma at any time }\left[\mathrm{Bq} \cdot \mathrm{L}^{-1}\right] ; \\
\mathrm{C}= & \text { concentration of glucose in blood } \\
& {\left[\mathrm{mmol} \cdot \mathrm{L}^{-1}\right] ; } \\
(\mathrm{C})_{\mathrm{t}}= & \text { concentration of glucose in blood at } \\
& \text { any time }\left[\mathrm{mmol} \cdot \mathrm{L}^{-1}\right] ; \\
\mathrm{SA}= & \text { specific radioactivity of glucose } \\
& {\left[\mathrm{Bq} \cdot \mathrm{mmol}^{-1}\right] ; } \\
(\mathrm{SA})_{\mathrm{t}}= & \mathrm{specific} \mathrm{radioactivity} \mathrm{at} \mathrm{any} \mathrm{time} \\
& {\left[\mathrm{Bq} \cdot \mathrm{mmol}^{-1}\right] ; } \\
\mathrm{AUC}= & \text { area under the }(\mathrm{SA})_{\mathrm{t}} \text { vs. time curve } \\
& {\left[\mathrm{Bq} \cdot \mathrm{mmol}^{-1} \cdot \mathrm{min}\right] ; } \\
\text { Rate constant }= & \text { rate constant of glucose turnover } \\
& {\left[\mathrm{min}{ }^{-1}\right] ; } \\
\mathrm{V}= & \text { fractional distribution volume of glu- } \\
& \text { cose (fractional glucose space) }\left[\mathrm{L} \cdot \mathrm{kg}^{-}\right. \\
& \left.{ }^{1}\right] .
\end{aligned}
$$

The $(\mathrm{SA})_{\mathrm{t}}$ of glucose was obtained by dividing the radioactivity of glucose per unit volume by the glucose concentration:

$$
(\mathrm{SA})_{\mathrm{t}}\left[\mathrm{Bq} \cdot \mathrm{mmol}^{-1}\right]=\frac{(A)_{t}}{(C)_{t}} \frac{\left[B q \cdot l^{-1}\right]}{\left[\mathrm{mmol} \cdot \mathrm{l}^{-1}\right]}
$$

The glucose concentration before and during the DLBHB infusion varied only by $4.6 \pm 3 \%$. Tracer radioactivity per milliliter of plasma was, therefore, divided by the mean glucose concentration, which was present during the 1-h sampling period. The (SA)t values from the 60 -min sampling periods after bolus injection of $\left[{ }^{3} \mathrm{H}\right]-$ glucose represented only a relatively small segment of the decay curve. The data points were mathematically extrapolated to $t_{0}$, (time of marker injection) and to a cut-off point beyond $60 \mathrm{~min}$, for which the marker 
concentration was $<1 \%$ of $(\mathrm{SA})_{0}$. This time equaled about $240 \mathrm{~min}$.

For extrapolation of $(\mathrm{SA})_{\mathrm{t}}$, the values were fitted to a two exponential equation of the form:

$$
(\mathrm{SA})_{\mathrm{t}}\left[\mathrm{Bq} \cdot \mathrm{mmol}^{-1}\right]=\mathrm{E}_{1} \exp \left(-\mathrm{k}_{1} \cdot \mathrm{t}\right)+\mathrm{E}_{2} \exp \left(-\mathrm{k}_{2} \cdot \mathrm{t}\right) .
$$

The coefficients $\left(\mathrm{E}_{1}, \mathrm{E}_{2}\left[\mathrm{~Bq} \cdot \mathrm{mmol}^{-1}\right]\right)$ and the exponents $\left(\mathrm{k}_{1}, \mathrm{k}_{2}\left[\mathrm{~min}^{-1}\right]\right)$ were estimated using the program Sigmaplot (SPSS Science Software GmbH, Erkrath, Germany). To prevent overrating of high radioactivity values during iteration, the squares of deviation of the curve from the measured data were weighted by division through the squares of the data. The radioactivity concentration per milliliter of blood plasma $(\mathrm{A})_{t} \mathrm{vs}$. time was extrapolated by the same procedure. The $(\mathrm{SA})_{\mathrm{t}}$ from 0 to 240 min was used to calculate AUC.

The turnover of glucose in $1 \mathrm{~L}$ of its distribution volume (normalized glucose turnover) was calculated by dividing $(\mathrm{A})_{0}$ by AUC:

\section{Normalized glucose turnover $\left[\mathrm{mmol} \cdot \mathrm{L}^{-1} \cdot \mathrm{min}^{-1}\right.$ ]}

$$
=\frac{(A)_{0}}{A U C} \frac{\left[B q \cdot l^{-1}\right]}{\left[B q \cdot m m o l^{-1} \cdot \min \right]} .
$$

The AUC of the second marker injection was confounded by carryover of tracer from the first $\left[{ }^{3} \mathrm{H}\right]$-glucose injection. This carryover amounted to $5.9 \pm 6.7 \%$ $(\bar{x} \pm \mathrm{SD})$ of the AUC of the second marker injection. The value was estimated from the extrapolated radioactivity vs. time curve of the first marker injection between 3 and $7 \mathrm{~h}$ and was subtracted from the AUC of the second marker injection curve.

From the normalized glucose turnover per liter distribution volume, the turnover of glucose per unit body weight per minute $\left[\mathrm{mmol} \cdot \mathrm{kg}^{-1} \cdot \mathrm{min}^{-1}\right]$ was estimated by multiplying the normalized glucose turnover with the fractional distribution volume of glucose $(\mathrm{V})\left[\mathrm{L} \cdot \mathrm{kg}^{-1}\right]$. The $(\mathrm{V})$ was calculated by dividing the injected dose of marker $[\mathrm{Bq}]$ by the extrapolated marker concentration at zero time $\left[\mathrm{Bq} \cdot \mathrm{L}^{-1}\right]$ and by the BW of the ewe $[\mathrm{kg}]$.

$$
\mathrm{V}\left[\mathrm{L} \cdot \mathrm{kg}^{-1}\right]=\frac{\text { dose of marker }}{(A)_{0} \cdot B W} \frac{[B q]}{\left[B q \cdot l^{-1}\right] \cdot[k g]}
$$

The rate constant of glucose turnover was calculated by dividing $(\mathrm{SA})_{0}$ by AUC.

$$
\text { Rate constant }\left[\mathrm{min}^{-1}\right]=\frac{(S A)_{0}}{A U C} \frac{\left[B q \cdot \mathrm{mmol}^{-1}\right]}{\left[B q \cdot \mathrm{mmol}^{-1} \cdot \mathrm{min}\right]} .
$$

For further details of calculation see (Schlumbohm and Harmeyer, 1999).

\section{Statistics}

The parameters of glucose metabolism were tested in a one-way ANOVA for the presence of significant differences between the animals. No significant differences existed between animals. It was intended to test the parameters of glucose kinetics in a two-way ANOVA with repeated measures (RM) for the presence of significant effects of reproductive states and of hyperketonemia. For this test, the differences of the data pairs were tested for normality and equal variance. This analysis showed that the original data groups were normally distributed, but the differences between data pairs, used for significance testing, were not. The effects of $\mathrm{BHB}$ and reproductive states were therefore examined by a nonparametric test in a one-way RM ANOVA on ranks with 6 different conditions, i.e., 2 for normo- and hyperketonemia in each of the 3 reproductive states (pregnancy, lactation, and nonpregnant nonlactating). Significant differences between group pairs were evaluated by the Student-Newman-Keuls test. This statistical approach provided no information on interactions between BHB effects and reproductive states. The significant values between combinations of the 6 conditions were, however, evenly distributed. This observation indicated that there was no significant interaction between the 3 reproductive states and the $\pm \mathrm{BHB}$ conditions. The 3 reproductive states were regarded as independent from each other. They represented different hormonal and metabolic conditions. The statistical program SigmaStat (SPSS Science Software Scientific, Erkrath, Germany) was used for the calculations. Because the original datasets are normally distributed, these values are presented in the figures as arithmetic means $\pm \mathrm{SD}$.

\section{RESULTS}

Table 1 presents the parameters of glucose metabolism in normo- and hyperketonemic sheep with statistical tests of differences between reproductive states. Figure 2 illustrates results of statistical testing of hyperketonemia on the kinetic values of glucose. Table 3 shows values of BHB metabolism during normo- and hyperketonemia and indicates differences between reproductive states.

\section{Influence of Reproductive State}

The concentration of glucose in blood plasma was statistically not different in nonpregnant nonlactating, pregnant, and lactating sheep within normo- and hyperketonemia. The rate constant of glucose turnover had significantly increased in normoketonemic lactating ewes by more than $50 \%$ compared with both nonpreg- 


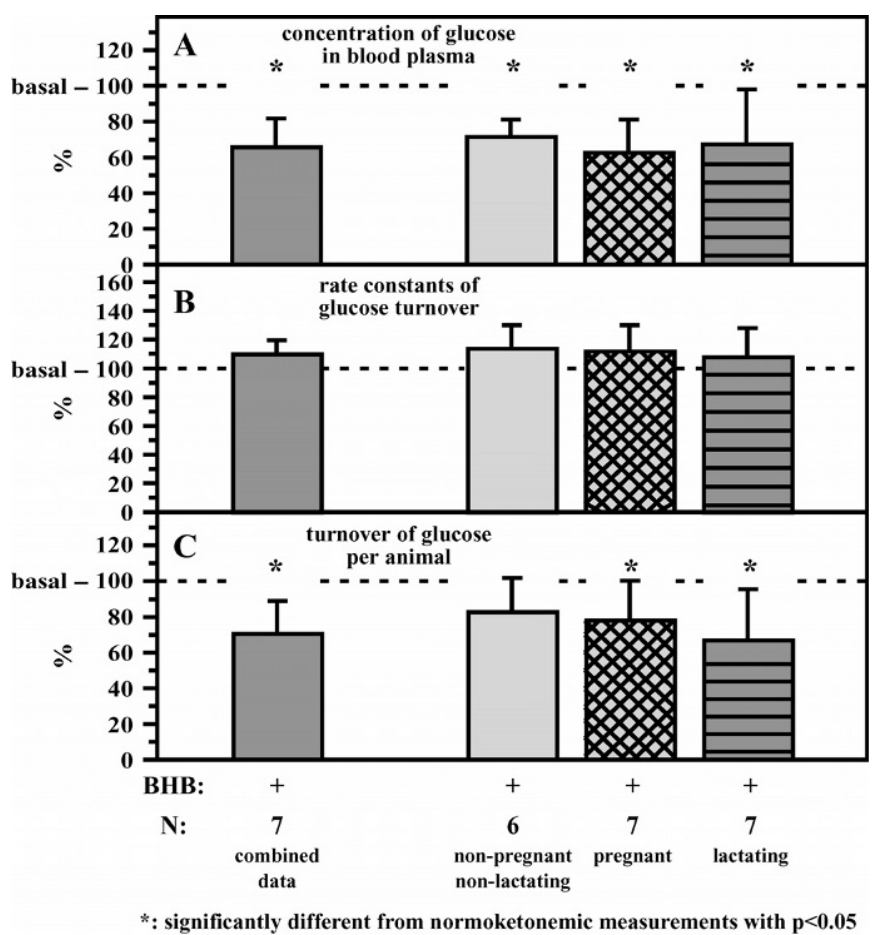

Figure 2. Kinetic parameters of glucose metabolism during hyperketonemia during 3 reproductive states. The values are presented as percent of the corresponding normoketonemic value $(=100 \%)$. This was obtained from the same animal in the same experiment $(\mathrm{N}=7$; $\bar{x} \pm \mathrm{SD})$.

nant nonlactating and pregnant sheep. This significant stimulatory effect of lactation was also present about at the same extent under hyperketonemic conditions. The increase in the rate constant of glucose turnover during lactation was paralleled by a significant increase in the mass rate of glucose turnover. Glucose turnover was increased by $45 \%$ during late pregnancy and by
$119 \%$ during lactation, relative to the mean value for nonpregnant nonlactating ewes. This sequence was qualitatively the same during normo- and hyperketonemia.

\section{Influence of Hyperketonemia}

Elevation of the BHB concentration in plasma from $0.7 \pm 0.6 \mathrm{mmol} \cdot \mathrm{l}^{-1}$ to $6.0 \pm 1.6 \mathrm{mmol} \cdot \mathrm{l}^{-1}(\bar{x} \pm \mathrm{SD})$ significantly lowered the plasma glucose concentration. This effect was significant and was the same during all three reproductive states. For the combined values this amounted to $30 \pm 18 \%(\bar{x} \pm \mathrm{SD})$. The rate constants of glucose turnover were not significantly affected by hyperketonemia. Glucose turnover was significantly depressed by hyperketonemia in pregnant and in lactating sheep by $20 \pm 9$ and $29 \pm 12 \%$, respectively, compared with the normoketonemic condition. The same trend was also apparent in the nonpregnant nonlactating animals. Hyperketonemia depressed glucose turnover significantly by an average of $25 \pm 5 \%$ for the combined values for the three reproductive states.

\section{BHB Status}

Basal concentrations of BHB in plasma did not differ significantly between reproductive states. Mean BHB concentrations tended to be higher during pregnancy and lactation than in the nonpregnant nonlactating state. Continuous BHB-infusions significantly elevated BHB concentrations up to 5 to $7 \mathrm{mmol} \cdot \mathrm{L}^{-1}$. The BHB concentration in blood increased per unit dose of BHB $\left[\mathrm{mmol} \cdot \mathrm{kg}^{-1} \cdot \mathrm{min}^{-1}\right]$ by 252 to $309 \mathrm{mmol} \cdot \mathrm{L}^{-1}$. The values did not differ between reproductive states.

Table 3. Parameters of D- $\beta$-hydroxybutyrate (D-BHB) metabolism in plasma before and during the DL$\mathrm{BHB}$ infusion during three reproductive states $(\bar{x} \pm \mathrm{SD}, \mathrm{N}=7)$. D-BHB infusion rates represent the proportion of the D-BHB isomer in the DL-BHB racemate.

\begin{tabular}{lccc}
\hline & $\begin{array}{c}\text { Nonpregnant } \\
\text { nonlactating } \\
(6 \text { exp. })\end{array}$ & $\begin{array}{c}\text { Pregnant } \\
(7 \text { exp. })\end{array}$ & $\begin{array}{c}\text { Lactating } \\
(7 \text { exp. }\end{array}$ \\
\hline $\begin{array}{l}\text { Basal D-BHB concentrations in } \\
\text { blood plasma }\left(m m o l \cdot L^{-1}\right)\end{array}$ & $0.40 \pm 0.16$ & $0.99 \pm 0.78$ & $0.79 \pm 0.43$ \\
$\begin{array}{l}\text { Continuous D-BHB infusion rates } \\
\left(\mathrm{mmol} \cdot \mathrm{kg}^{-1} \cdot \mathrm{min}^{-1}\right)\end{array}$ & $0.022 \pm 0.0^{\mathrm{a}}$ & $0.0143 \pm 0.0047^{\mathrm{b}}$ & $0.0243 \pm 0.0039^{\mathrm{a}}$ \\
$\begin{array}{l}\text { Steady-state D-BHB } \\
\text { concentrations in blood plasma } \\
\text { during infusion }\left(\mathrm{mmol} \cdot \mathrm{L}^{-1}\right)\end{array}$ & $5.94 \pm 0.90^{\mathrm{a}, \mathrm{b}}$ & $4.92 \pm 1.23^{\mathrm{a}}$ & $7.09 \pm 1.76^{\mathrm{b}}$ \\
$\begin{array}{l}\text { Increases of D-BHB in plasma per } \\
\text { unit dose of D-BHB }\end{array}$ & $252 \pm 36$ & $309 \pm 144$ & $266 \pm 83$ \\
$\left(\frac{\Delta\left(\mathrm{mmol} \cdot \mathrm{L}^{-1}\right)}{\left(m \mathrm{~mol} \cdot \mathrm{kg}^{-1} \cdot \mathrm{min}^{-1}\right)}\right)$ & & & \\
\hline
\end{tabular}

${ }^{\mathrm{a}, \mathrm{b}}$ Different superscripts denote significant differences $(P<0.05)$. 


\section{DISCUSSION}

\section{Experimental Setup and Calculation of Kinetic Parameters}

The animals were accompanied by a companion sheep and had been familiarized with the experimental conditions. They were not subjected to physical stress consistent with the lack of random fluctuations in basal plasma glucose concentration during the sampling periods. Feeding related short-term fluctuations were also absent due to overnight fasting. The 12-h fast appears to have no influence on glucose homeostasis. Similar observations have been reported by Van der Walt et al. (1980), who showed that the glucose turnover in sheep did not decline before the second day of fasting.

For calculation of the kinetic parameters of glucose metabolism, a noncompartmental (stochastic) method was used. The advantages and limitations of the noncompartmental approach compared with the compartmental method has extensively been discussed by Radziuk and Hetenyi (1982), Katz et al. (1974a, 1974b), Shipley and Clarke (1972) and Normand and Fortier (1970).

\section{Interpretation of Changes in Kinetic Parameters of Glucose Metabolism}

The elevated steady-state BHB concentrations in pregnant ewes were slightly smaller than those in nonpregnant nonlactating and in lactating sheep. This was due to slightly reduced BHB infusion rates that were administered to pregnant animals to avoid abortion induced by hyperketonemic stress.

It was shown by Bergman (1973), Bergman et al. (1974), Wilson et al. (1983), and others that intestinal absorption of glucose in sheep is negligible by $12 \mathrm{~h}$ after feeding. From this we assumed that the rates of glucose turnover measured in this study represented hepatic entry rates (total appearance rates) of glucose and rates of total disposal (disappearance) of glucose from blood.

The turnover rate of glucose calculated with $\left[2-{ }^{3} \mathrm{H}\right]-$ glucose as the tracer is about $13 \%$ greater than when measured simultaneously with $\left[\mathrm{U}-{ }^{14} \mathrm{C}\right]$-glucose (Judson and Leng, 1972). It provides an estimate of the rate of irreversible disposal of the $\left[2-{ }^{3} \mathrm{H}\right]$-label from the glucose molecule (Katz and Rognstad, 1976). In futile cycling of glucose, detritiation from position 2 would occur between glucose $6 \mathrm{P}$ and glucose. Cycling at the glucose $6 \mathrm{P}$ level appears to be absent in ruminants since Judson and Leng (1972) found no difference in irreversible loss rates of glucose between $\left[2-{ }^{3} \mathrm{H}\right]-$ and $\left[3-{ }^{3} \mathrm{H}\right]$-glucose. Detritiation of ${ }^{3} \mathrm{H}$ from position 3 occurs between glucose $6 \mathrm{P}$ and fructose $6 \mathrm{P}$ (Altzuler et al., 1975; Katz et al., 1976; Bell et al., 1986).
Theoretically, a change in one or more kinetic parameters of glucose metabolism could originate from a primary change of glucose production or glucose utilization. The true cause of such a change can often be deduced from the relative changes in the kinetic parameters. If, for example, under a given experimental condition the glucose concentration in blood was declined, the rate constant of glucose turnover $\left[\mathrm{min}^{-1}\right]$ was increased and the glucose turnover $\left[\mathrm{mmol} \cdot \mathrm{kg}^{-1} \cdot \mathrm{min}^{-1}\right]$ remained unchanged, this would indicate that the changes were triggered by an increased demand in peripheral glucose that could not be met by an equivalent increase in hepatic glucose production.

\section{Effect of Reproductive State on Glucose Metabolism}

Glucose turnover in our nonpregnant nonlactating, late pregnant, and lactating sheep was $0.80,1.16$, and $1.76 \mathrm{mmol} \cdot \mathrm{min}^{-1}$, respectively, and was in good agreement with values from many other investigators (Bergman et al., 1970; Steel and Leng, 1973; Hay et al., 1983; Wilson et al., 1983; Petterson et al., 1993). Steel and Leng (1973) and Wilson et al. (1983) showed that the increase in glucose turnover rate during pregnancy and lactation compared with the nonpregnant nonlactating state resulted from composite effects, i.e., an increased efficiency of hepatic gluconeogenesis from glucose precursors due to a metabolic adaptation and an increased availability of glucose precursors due to an increased food intake. With regard to our data, this increase was mainly due to an increase of the rate constant of glucose turnover with concomitantly more or less unchanged plasma glucose concentrations (Table 1). This is evidence for the suggestion that the first signal for this metabolic change is an increased demand of glucose coming from the fetoplacental unit or the mammary gland. Probably the increased glucose demand initially leads to an increased rate constant of glucose turnover, followed by an increased hepatic glucose output.

\section{Influence of Hyperketonemia on Glucose Production}

Acute hyperketonemia significantly depressed plasma glucose concentration regardless of the reproductive state of the sheep. This constitutes the main finding of this study. The degree of experimentally induced hyperketonemia ( 5 to $7 \mathrm{mmol} \cdot \mathrm{L}^{-1}$ ) was comparable to that observed in clinical cases of pregnancy toxemia (Henze et al., 1998), and the depressive effect is also likely to be present under field conditions and, in 
our opinion, has a major impact on the pathogenesis of the ketotic disorder.

Krebs (1966) first hypothesized that bovine ketosis might develop in a state of increased glucose demand, leading to a relative lack of oxaloacetate in the liver and then followed by an abnormal hepatic production of ketone bodies. Not in line with this hypothesis is the observation that in sheep the rate of glucose production is usually twice as high during lactation than in late pregnancy without a concomitant increase in ketone body formation. Moreover, Steel and Leng (1973) and Bergman (1973) noted that in sheep higher rates of glucose synthesis were usually associated with lower rather than higher rates of ketone body formation. Conversely, sheep with clinical signs of pregnancy toxemia and reduced food intake usually have a significantly reduced glucose turnover, whereas the rate of ketogenesis is very high (Kronfeld and Simesen, 1961).

Bergman (1971) attempted to explain these inconsistencies by postulating distinct metabolic changes in pregnant ketotic sheep during which the liver would switch from complete oxidation of FFA to ketogenesis and triglyceride synthesis. He further speculated that an additional yet unknown "hepatic factor" might be responsible for the increased hepatic output of ketone bodies. From our findings, it appears that the elevated levels of ketone bodies in blood constitute a component of the "hepatic factor" as suggested by Bergman (1971) that firstly depresses glucose production and secondly stimulates ketogenesis.

Elevation of the BHB concentration in blood declined plasma glucose concentration and glucose turnover, whereas the rate constant of glucose turnover remained unchanged. This response characteristic shows that the reduction in glucose turnover initially resulted from a decrease in the glucose production rate with no primary change in the demand of glucose. The decreased provision of hepatic glucose then led to a decrease in blood glucose concentration paralleled by a concomitant reduction in glucose utilization. Hyperketonemia appears not to affect peripheral glucose utilization. The same response characteristic as reported here was observed in experiments with pigs (Müller et al., 1984), showing that a general principle seems to underlie the depressive effect of elevated ketones on glucose production and turnover. The depressive effect of elevated ketones further reduces hepatic glucose production and exaggerates the development of ketosis. We therefore believe that hyperketonemia constitutes a causative factor in the development of clinical ketosis in sheep and probably also in cattle. The negative feedback of hyperketonemia on glucose production renders the pregnant or lactating ruminant into a vicious circle. One way or other, a relative shortage of glucose probably creates a lipolytic signal that increases the release of FFA from adipose tissue. The elevated concentrations of FFA in blood stimulate hepatic uptake of FFA and the formation of ketone bodies. The increased concentration of ketones in blood further depresses the hepatic rate of glucose production, which augments the shortage of glucose and increases the lipolytic signal. Besides this sequence of events, there is indication that a poor supply of glucose and glucose precursors to liver cells also stimulates hepatic ketogenesis at the cellular level (Herdt, 2000). This effect would further enhance the development of the ketotic condition. It has repeatedly been shown that the risk of developing ketosis increases when the weight loss and the energy deficit increases during late pregnancy and early lactation (Gerloff, 2000; Enjalbert et al., 2001). Based on the results of this study, the phenomenon can be explained as follows: greater mobilization rates of body reserves initially lead to higher FFA concentrations in blood plasma, to a higher stimulus of hepatic ketogenesis, and to a greater depressing signal on hepatic gluconeogenesis. This increases the risk of ketosis in over-conditioned cows and sheep.

Depression of hepatic gluconeogenesis by hyperketonemia occurred during all three reproductive states. This further supports the suggestion that additional but yet unknown (hormonal and/or biochemical) factors must be involved in the development of pregnancy toxemia.

\section{ACKNOWLEDGMENTS}

This study was supported by the Deutsche Forschungsgemeinschaft, grant no. HA 542/11-2.

\section{REFERENCES}

Altszuler, N., A. Barkai, C. Bjerknes, B. Gottlieb, and R. Steele. 1975. Glucose turnover values in the dog obtained with various species of labeled glucose. Am. J. Physiol. 229:1662-1667.

Baird, G. D., R. J. Heitzman, K. G. Hibbitt, and G. D. Hunter. 1974. Clinical problems of preventive medicine. Bovine ketosis: A review with recommendations for control and treatment. Part II. Br. Vet. J. 130:318-326.

Baron, A. D., G. Brechtel, and S. V. Edelman. 1989. Effects of free fatty acids and ketone bodies on in vivo non-insulin-mediated glucose utilization and production in humans. Metabolism 38:1056-1061.

Battaglia, F. C., and G. Meschia. 1988. Fetal nutrition. Annu. Rev. Nutr. 8:43-61.

Bell, P. M., R. G. Firth, and R. A. Rizza. 1986. Effects of hyperglycemia on glucose production and utilization in humans. Measurement with $\left[2-{ }^{3} \mathrm{H}\right]-,\left[3-{ }^{3} \mathrm{H}\right]-$, and $\left[6-{ }^{14} \mathrm{C}\right]$ glucose. Diabetes 35:642-648.

Bergman, E. N. 1971. Hyperketonemia-ketogenesis and ketone body metabolism. J. Dairy Sci. 54:936-948.

Bergman, E. N. 1973. Glucose metabolism in ruminants as related to hypoglycemia and ketosis. Am. J. Physiol. 215:865-873.

Bergman, E. N., D. J. Starr, and S. Reulein, Jr. 1968. Glycerol metabolism and gluconeogenesis in the normal and hypoglcemic ketotic sheep. Am. J. Physiol. 215:874-880. 
Bergman, E. N., M. L. Katz, and C. F. Kaufman. 1970. Quantitative aspects of hepatic and portal glucose metabolism and turnover in sheep. Am. J. Physiol. 219:785-793.

Bergman, E. N., R. P. Brockman, and C. F. Kaufman. 1974. Glucose metabolism in ruminants: Comparison of whole-body turnover with production by gut, liver and kidneys. Fed. Proc. 33:18491854

Beylot, M., Y. Khalfallah, J. P. Riou, R. Cohen, S. Normand, and R. Mornex. 1986. Effects of ketone bodies on basal and insulinstimulated glucose utilization in man. J. Clin. Endocrinol. Metab. 63:9-15.

Enjalbert, F., M. C. Nicot, C. Bayourthe, and R. Moncoulon. 2001. Ketone bodies in milk and blood of dairy cows: Relationship between concentrations and utilization for detection of subclinical ketosis. J. Dairy Sci. 84:583-589.

Geishauser, T., K. Leslie, D. Kelton, and T. Duffield. 1998. Evaluation of five cowside tests for use with milk to detect subclinical ketosis in dairy cows. J. Dairy Sci. 81:438-443.

Gerloff, B. J. 2000. Dry cow management for the prevention of ketosis and fatty liver in dairy cows. Vet. Clin. North Am. Food. Anim. Pract. 16:283-292.

Hay, W. W., Jr., J. W. Sparks, R. B. Wilkening, F. C. Battaglia, and G. Meschia. 1983. Partition of maternal glucose production between conceptus and maternal tissues in sheep. Am. J. Physiol. 245:E347-E350.

Heitmann, R. N., D. J. Dawes, and S. C. Sensenig. 1987. Hepatic ketogenesis and peripheral ketone body utilization in the ruminant. J. Nutr. 117:1174-1180.

Heitmann, R. N., and J. M. Fernandez. 1986. Autoregulation of alimentary and hepatic ketogenesis in sheep. J. Dairy Sci. 69:1270-1281.

Henze, P., K. Bickhardt, H. Fuhrmann, and H. P. Sallmann. 1998. Spontaneous pregnancy toxaemia (ketosis) in sheep and the role of insulin. Zentralbl. Vet. Med. A 45:255-266.

Herdt, T. H. 2000. Ruminant adaptation to negative energy balance. Influences on the etiology of ketosis and fatty liver. Vet. Clin. North Am. Food Anim. Pract. 16:215-230.

Herdt, T. H., J. B. Stevens, J. Linn, and V. Larson. 1981. Influence of ration composition and energy balance on blood beta -hydroxybutyrate (ketone) and plasma glucose concentrations of dairy cows in early lactation. Am. J. Vet. Res. 42:1177-1180.

Judson, G. J., and R. A. Leng. 1972. Estimation of the total entry rate and resynthesis of glucose in sheep using glucoses uniformly labelled with ${ }^{14} \mathrm{C}$ and variously labelled with ${ }^{3} \mathrm{H}$. Aust. J. Biol. Sci. 25:1313-1332.

Katz, J., H. Rostami, and A. Dunn. 1974a. Evaluation of glucose turnover, body mass and recycling with reversible and irreversible tracers. Biochem. J. 142:161-170.

Katz, J., A. Dunn, M. Chenoweth, and S. Golden. 1974b. Determination of synthesis, recycling and body mass of glucose in rats and rabbits in vivo ${ }^{3} \mathrm{H}$-and ${ }^{14} \mathrm{C}$-labelled glucose. Biochem. J. 142:171-183.

Katz, J., and R. Rognstad. 1976. Futile cycles in the metabolism of glucose. Curr. Top. Cell. Regul. 10:237-289.

Katz, J., S. Golden, A. Dunn, and M. Chenoweth. 1976. Estimation of glucose turnover in rats in vivo with tritium labelled glucoses. Hoppe Seylers Z. Physiol. Chem. 357:1387-1394.

Krebs, H. A. 1966. Bovine ketosis. Vet. Rec. 78:187-192.

Kronfeld, D. S. 1971. Hypoglycemia in ketotic cows. J. Dairy Sci. $54: 949-961$.

Kronfeld, D. S., and M. G. Simesen. 1961. Glucose biokinetics in ovine pregnancy toxemia. Cornell Vet. 51:478-488.
Lacetera, N., U. Bernabucci, B. Ronchi, and A. Nardone. 2001. Effects of subclinical pregnancy toxemia on immune responses in sheep. Am. J. Vet. Res. 62:1020-1024.

Lean, I. J., M. L. Bruss, R. L. Baldwin, and H. F. Troutt. 1992. Bovine ketosis: A review. II. Biochemistry and prevention. Vet. Bull. 62:1-14.

Marteniuk, J. V., and T. H. Herdt. 1988. Pregnancy toxemia and ketosis of ewes and does. Vet. Clin. North Am. Food Anim. Pract. 4:307-315.

Mebane, D., and L. L. Madison. 1964. Hypoglycemic action of ketones. I. Effects of ketones on hepatic glucose output and peripheral glucose utilization. J. Lab. Clin. Med. 63:177-192.

Morriss, F. J., Jr., R. D. Boyd, E. L. Makowski, G. Meschia, and F C. Battaglia. 1974. Umbilical V-A differences of acetoacetate and beta-hydroxybutyrate in fed and starved ewes. Proc. Soc. Exp. Biol. Med. 145:879-883.

Müller, M. J., U. Paschen, and H. J. Seitz. 1984. Effect of ketone bodies on glucose production and utilization in the miniature pig. J. Clin. Invest. 74:249-261.

Normand, M., and C. Fortier. 1970. Numerical versus analytical integration of hormonal disappearance data. Can. J. Physiol. Pharmacol. 48:274-281.

Petterson, J. A., F. R. Dunshea, R. A. Ehrhardt, and A. W. Bell. 1993. Pregnancy, and undernutrition alter glucose metabolic responses to insulin in sheep. J. Nutr. 123:1286-1295.

Radziuk, J., and G. Hetenyi, Jr. 1982. Modelling and the use of tracers in the analysis and exogenous control of glucose homeostasis. Pages 73-142 in Quantitative Approaches to Metabolism. The Role of Tracers and Models in Clinical Medicine. D. G. Cramp, ed. John Wiley \& Sons, New York, NY.

Robinson, A. M., and D. H. Williamson. 1980. Physiological roles of ketone bodies as substrates and signals in mammalian tissues. Physiol. Rev. 60:143-187.

Schlumbohm, C., and J. Harmeyer. 1999. Effect of hypocalcaemia on glucose metabolism in hyperketonaemic piglets. Exp. Physiol. 84:707-723.

Shaw, J. H. F., and R. R. Wolfe. 1984. Influence of beta-hydroxybutyrate infusion on glucose, and free fatty acid metabolism in dogs. Am. J. Physiol. 247:E756-E764.

Shipley, R. A., and R. E. Clark. 1972. Tracer Methods for in Vivo Kinetics, Theory, and Applications. Academic Press, New York, NY.

Somogyi, M. 1952. Determination of blood sugar. J. Biol. Chem. 195:19-23.

Steel, J. W., and R. A. Leng. 1973. Effects of plane of nutrition, and pregnancy on gluconeogenesis in sheep. 1. The kinetics of glucose metabolism. Br. J. Nutr. 30:451-473.

Van der Walt, J. G., J. Procos, and F. J. Labuschagne. 1980. Glucose turnover tolerance, and insulin response in wethers ewes, and pregnant ewes in the fed, and fasted state. Onderstepoort J. Vet. Res. 47:173-178.

Van Saun, R. J. 2000. Pregnancy toxemia in a flock of sheep. J. Am Vet. Med. Assoc. 217:1536-1539.

Weekes, T. E. C. 1979. Carbohydrate metabolism. Pages 187-209 in Digestive Physiology and Nutrition of Ruminants. D. C. Church, ed. Oxford Press, Portland, UK.

Williamson, D. H., J. Mellanby, and H. A. Krebs. 1962. Enzymatic determination of $\mathrm{D}(-)$-beta-hydroxybutyric acid, and acetoacetic acid in blood. Biochem. J. 82:90-96.

Wilson, S., J. C. MacRae, and P. J. Buttery. 1983. Glucose production, and utilization in nonpregnant, pregnant, and lactating ewes. Br. J. Nutr. 50:303-316. 